\title{
A Portrait of Copper Processed by Equal Channel Angular Pressing
}

\author{
Ralph J. Hellmig ${ }^{1}$, Miloš Janeček ${ }^{2}$, Branislav Hadzima ${ }^{3}$, Oleg V. Gendelman ${ }^{4}$, \\ Michael Shapiro ${ }^{4}$, Xenia Molodova ${ }^{5}$, André Springer ${ }^{1}$ and Yuri Estrin ${ }^{6}$ \\ ${ }^{1}$ Department of Materials Science and Technology, Clausthal University of Technology, \\ Agricolastr. 6, 38678 Clausthal-Zellerfeld, Germany \\ ${ }^{2}$ Department of Physics of Materials, Charles University, Ke Karlovu 5, 12116 Praha 2, Czech Republic \\ ${ }^{3}$ Faculty of Mechanical Engineering, University of Žilina, 01026 Žilina, Slovak Republic \\ ${ }^{4}$ Faculty of Mechanical Engineering, Technion, Israel Institute of Technology, Haifa 32000, Israel \\ ${ }^{5}$ Institut für Metallkunde und Metallphysik, RWTH Aachen, 52056 Aachen, Germany \\ ${ }^{6}$ ARC Centre of Excellence for Design in Light Metals, Department of Materials Engineering, Monash University, \\ Clayton, VIC 3800, Australia and CSIRO Division of Manufacturing and Materials Technology, Clayton, Vic. 3168, Australia
}

Copper is one of the most important materials used for electrical connectors with a high thermal and electricial conductivity, and there is an ongoing demand to improve its mechanical properties without sacrificing other beneficial properties. A possible approach to achieving this aim is to use the method of severe plastic deformation to obtain an ultrafine grained microstructure. Significant grain refinement obtained by equal channel angular pressing (ECAP) leads to an improvement of mechanical, microstructural and physical properties. This paper gives an overview of a range of the properties that can be achieved by ECAP processing of pure copper including microstructural features, thermal stability, thermal conductivity and corrosion resistance. [doi:10.2320/matertrans.ME200717]

(Received July 10, 2007; Accepted August 10, 2007; Published September 28, 2007)

Keywords: copper, severe plastic deformation, equal channel angualar pressing, mechanical properties, thermal stability, thermal conductivity, corrosion behaviour

\section{Introduction}

In recent years, research activity in the area of severe plastic deformation (SPD) has increased due to some interesting properties which can be achieved by SPD in bulk materials. ${ }^{1)}$ Of specific interest for industrial applications are improved mechanical properties, especially a high strength, in conjunction with reasonable ductility, and the possibility to obtain high strain rate superplastic behaviour. ${ }^{2)}$ In addition, changes in physical properties owing to the small grain size are observed. As the diffusivity is significantly enhanced by severe plastic deformation, the SPD methods can be used to increase the speed of various kinetic processes, e.g. precipitation $^{3)}$ or such technologically important processes as nitriding of steels. ${ }^{4)}$

The present work was motivated by industry's demand for improving the mechanical properties of copper, particularly for use in connectors, without a detrimental effect on its overall properties profile. Alloying of copper leads to a significant increase in strength, but often the price is an appreciable loss of electrical and thermal conductivity. To investigate the viability of grain refinement by severe plastic deformation in achieving a balance between the required properties, investigations on the mechanical properties, the thermal stability, the corrosion properties and the thermal resistivity were carried out. This paper summarises the results of these studies and demonstrates that it is possible to produce ultrafine-grained copper with the potential to be used for high strength connectors still allowing a good conductivity.

\section{Experimental}

ECAP of technical purity copper (99.95\%) was carried out using a split design die manufactured from tool steel $\mathrm{X} 38 \mathrm{CrMoV} 5$ 1. The angle between the entrance and the exit channels was $90^{\circ}$; a sharp die corner was used to maximize strain per ECAP pass. A typical specimen size was $10 \mathrm{~mm} \times 10 \mathrm{~mm} \times 100 \mathrm{~mm}$. An INSTRON 8502 universal testing machine (maximum load of $200 \mathrm{kN}$ ) was used in room temperature ECAP at typical speeds of eight millimetres per minute. To reduce frictional effects, molybdenum disulphide was used for lubrication.

For transmission electron microscopy (TEM) investigations on specimens prepared by mechanical and electrolytic polishing from middle sections of the ECAP processed billets, a Philips CM200 electron microscope operating at $200 \mathrm{kV}$ was used. Electrolytic polishing was carried out at $10^{\circ} \mathrm{C}$ using $50 \% \mathrm{H}_{3} \mathrm{PO}_{4}$ in a Tenupol 5 (Struers) jet polishing unit.

EBSD (electron backscatter diffraction) measurement on heat treated ECAP specimens were carried out using a LEO 1530 FEG Scanning Electron Microscope.

Mechanical properties were determined by testing tensile specimens in a conventional universal testing machine (INSTRON 5582) fitted with an extensometer. The applied strain rate was $10^{-3} \mathrm{~s}^{-1}$.

Thermal conductivity measurements were performed using a stationary method, ${ }^{5)}$ where a copper specimen and a reference specimen (Macor) of known thermal conductivity were subjected to the same unidirectional heat flux, which was generated by placing the specimens between a heated and a cooled platens. To minimize the thermal resistance between the two specimens and between the specimens and the platens, the specimens were mechanically polished. A thermally conducting graphite lubrication paste was also used at the contacts. (For more detail of the thermal conductivity measurement setup, see Ref. 6).) 


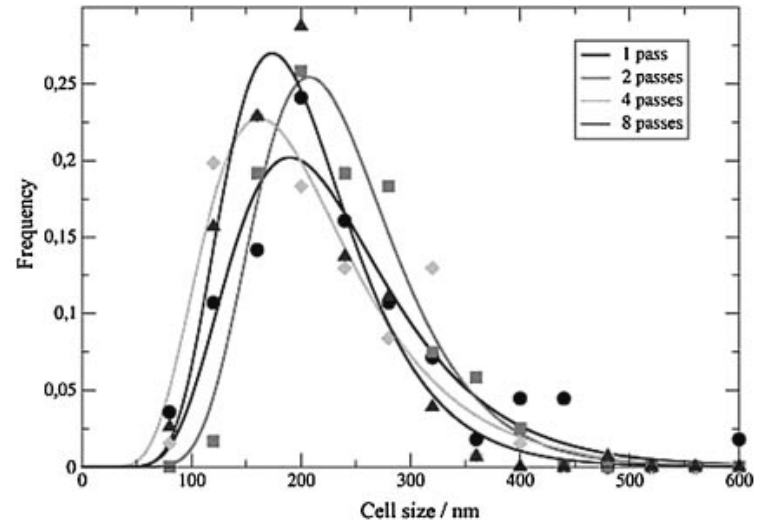

Fig. 1 Dislocation cell size distributions in technical purity copper after ECAP processing.

To investigate the corrosion behaviour, a Voltalab 10-PGZ 100 (Radiometer Analysis SYS, France) unit consisting of a conventional three electrode cell was used. A saturated calomel electrode (SCE) connected via a Haber-Luggin capillary was chosen as a reference electrode. Using teflon tape, a defined copper electrode surface area of approximately $20 \mathrm{~mm}^{2}$ was delineated. The solutions used as corrosive media were $1 \mathrm{kmol} / \mathrm{m}^{3} \mathrm{H}_{2} \mathrm{SO}_{4}$ and $3 \% \mathrm{NaCl}$. Prior to corrosion testing, the specimen surfaces were mechanically polished on a fine emery paper followed by an electropolishing procedure. After cathodic charging employed to remove oxide films which may have had formed, potentiodynamic scans with a speed of $1 \mathrm{mV} \mathrm{s}^{-1}$ were performed. After reaching the transpassive potential, the scans were terminated. More details on the corrosion measurements and the setup used are given in Ref. 7).

To investigate the influence of the corrosion pattern, particularly the degree of localization of corrosion attack, a Tesla BS343 scanning electron microscope operating at $15 \mathrm{kV}$ was used.

\section{Results}

\subsection{Effect of ECAP on the grain structure and the mechanical properties}

As already known, in case of pure copper ECAP leads to a significant grain refinement resulting in a microstructure with an average grain size of about $200 \mathrm{~nm}$ as determined by TEM. This structural refinement occurs already after the first ECAP pass, during which a large number of low angle grain boundaries are introduced in the microstructure. With an increase in the number of ECAP passes, an equiaxed grain structure is formed combined with an increase of the amount of newly formed high angle grain boundaries. Still, a significant number of low angle grain boundaries remain present in this kind of microstructure. ${ }^{8)}$ The evolution of the dislocation cell size can be seen in Fig. 1, which shows that almost no change in the typical structural scale produced in the first ECAP step occurs with subsequent ECAP passes. The cell size distribution was obtained by measuring the apparent cell diameter, which is given by the diameter of a circle of the same area as the cell investigated. A log-normal distribution appears to fit the cell size distribution data

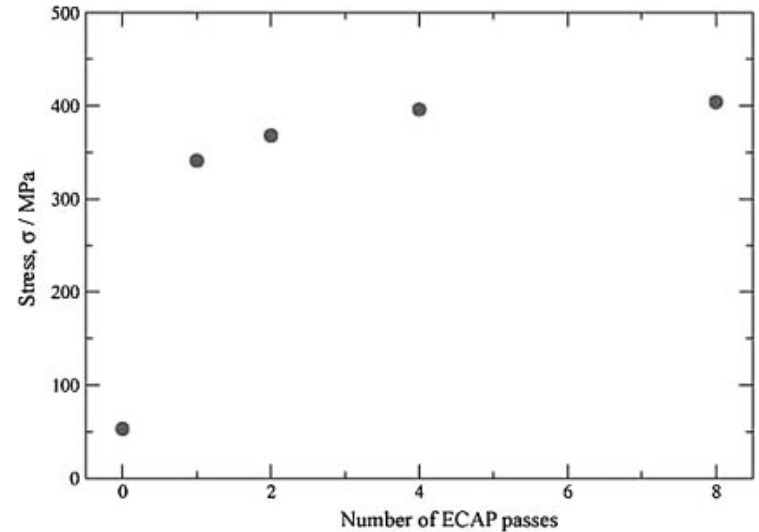

Fig. $20.2 \%$ proof stress of technical purity copper before and after ECAP processing.

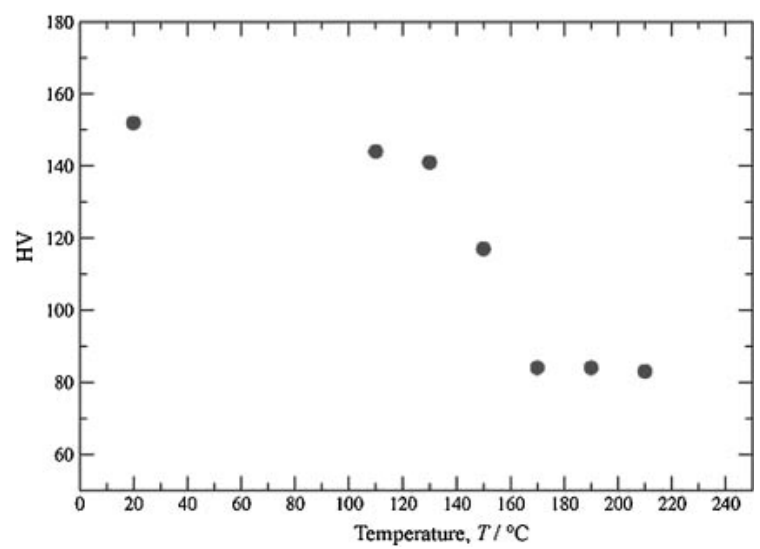

Fig. 3 Microhardness variation of ECAP processed copper (8 passes) with the temperature of isochronal annealing $(10 \mathrm{~min})$.

obtained from TEM analysis pretty well. However, a detailed analysis $^{6)}$ showed that a different function accounts for the cell size distribution more adequately than a log-normal one.

Investigations of the strength of copper after ECAP revealed a similar tendency, as can be seen from Fig. 2. Already after a single ECAP pass, the $0.2 \%$ proof stress increases significantly, to more than $300 \mathrm{MPa}$, and it hardly grows with further ECAP processing.

\subsection{Studies of thermal stability}

Generally, the increase of strength reported in the previous section is accompanied with a drop of ductility. To improve ductility, a thermomechanical route that combines ECAP with a suitable heat treatment can be followed. One of the ideas discussed in literature is to produce a bimodal microstructure and increase strength and ductility at the same time. ${ }^{9)}$ This was also shown to be beneficial with regard to the fatigue behaviour. ${ }^{10)}$

To accomplish this goal, the thermal stability of copper after ECAP needs to be known. In order to obtain these data, isochronal annealing (10 minutes) was performed on specimens after 8 ECAP passes in a temperature range of $100^{\circ} \mathrm{C}$ to $200^{\circ} \mathrm{C}$. Hardness tests were carried out to characterize thermal stability. The results of this investigation can be seen in Fig. 3. At about $150^{\circ} \mathrm{C}$ a strong decrease of the microhardness is observed. Figure 3 suggests that a bimodal 


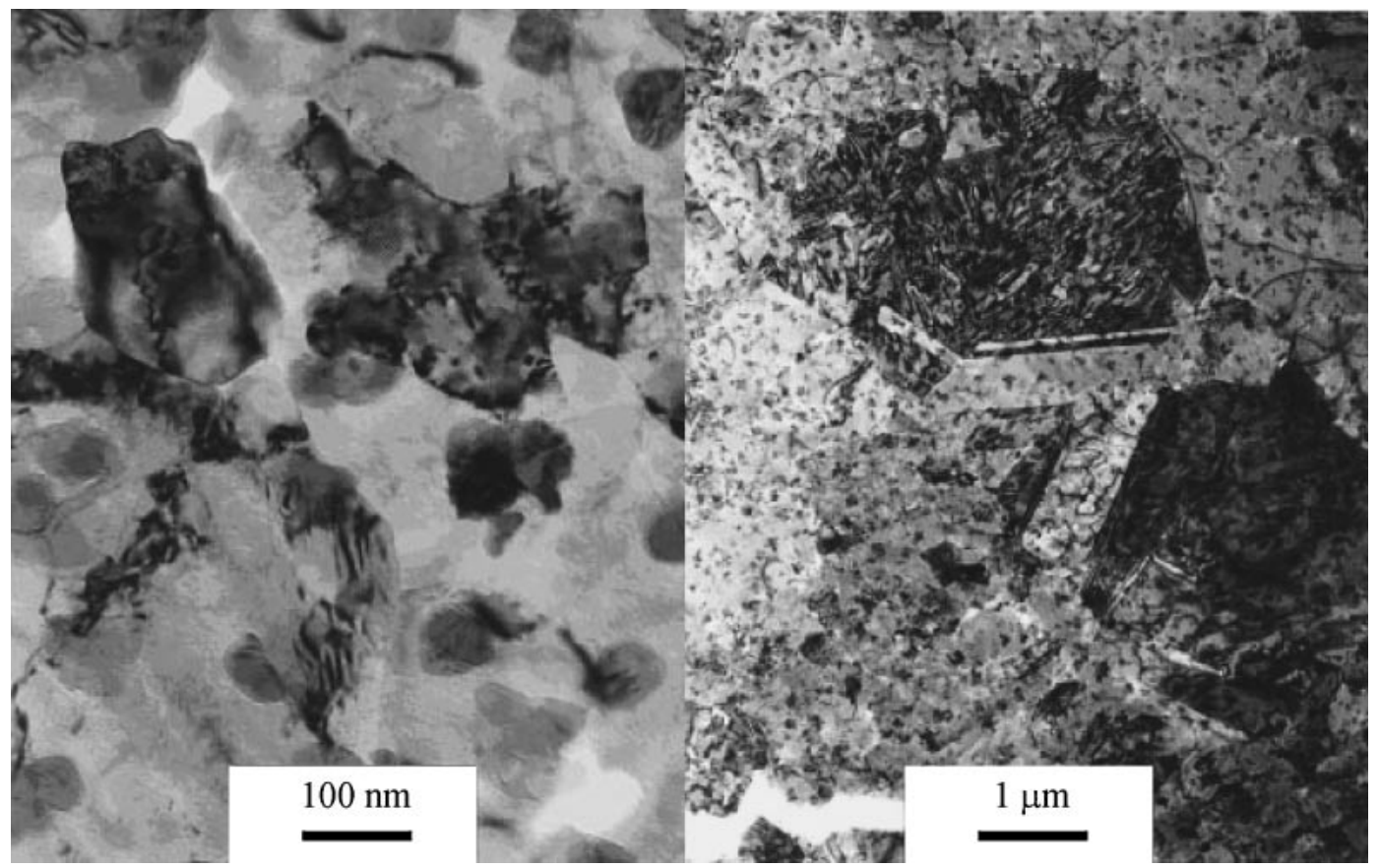

Fig. 4 TEM micrographs of ECAP processed copper (8 passes) after isochronal annealing $(10 \mathrm{~min})$, left: at $110^{\circ} \mathrm{C}$, right: at $150^{\circ} \mathrm{C}$.

microstructure may be obtained through using such isochronal heat treatment in the temperature range between $150^{\circ} \mathrm{C}$ and $170^{\circ} \mathrm{C}$ due to recrystallisation effects.

The influence of the mentioned heat treatment on the microstructure is presented in Fig. 4. The TEM micrograph on the left-hand side shows the structure after annealing at $110^{\circ} \mathrm{C}$. (The original microstructure exhibiting a grain size of about $200 \mathrm{~nm}$ can still be recognised in the micrograph.) The micrograph on the right-hand side shows parts of the microstructure after annealing at $150^{\circ} \mathrm{C}$, grain growth being obvious. Very sharp grain boundaries can also be seen. Numerous small grains of about $200 \mathrm{~nm}$ in size are still present after the $150^{\circ} \mathrm{C}$ heat treatment.

To get an overview picture of the structural changes after heat treatments, EBSD investigations were carried out. Figure 5 shows the orientation images after isochronal annealing at $110^{\circ} \mathrm{C}(\mathrm{a}), 150^{\circ} \mathrm{C}$ (b) and $170^{\circ} \mathrm{C}$ (c). After the $110^{\circ} \mathrm{C}$ annealing no significant change of the microstructure was observed. An ultrafine grain size and homogeneous grain distribution were still found. The fraction of high angle grain boundaries (HAGBs) as determined by EBSD was at about $48 \%$.

In Fig. 5(b), first changes in the microstructure are visible. Obviously, the annealing process at $150^{\circ} \mathrm{C}$ leads to the occurrence of first macroscopic recrystallised grains. This result is consistent with the TEM observations described before. Numerous ultrafine grains are present in the microstructure after the annealing. Again, the measured proportion of HAGBs was about $48 \%$.

Annealing at $170^{\circ} \mathrm{C}$ (Fig. 5(c)) led to a completely changed microstructure. It was still relatively fine-grained having an average grain size of $740 \mathrm{~nm}$, but large parts of this microstructure were recrystallised, and the fraction of HAGBs increased to about $93 \%$. Between large recrystallised grains there was still a sizeable amount of ultrafine grains leading to a bimodal grain size distribution.

The expected positive effect of the heat treatment on the mechanical properties is illustrated by Fig. 6. A significant increase in ductility is seen to be possible without compromising the strength too much. After heat treatment at $110^{\circ} \mathrm{C}$, hardly any changes in the tensile properties could be observed. An increase of the annealing temperature to $160^{\circ} \mathrm{C}$ or $170^{\circ} \mathrm{C}$ is seen to lead to an increase in ductility owing to the aforementioned bimodal microstructure. These results demonstrate that the use of an appropriate thermomechanical route makes it possible to establish a favourable combination of strength and ductility of technical purity copper simply by controlling its recrystallisation behaviour.

\subsection{Effect of ECAP on thermal conductivity}

Another property which is very important for the application of copper as a connector is its thermal and electrical conductivity (which are correlated through the WiedemannFranz law). As it is crucial to retain the high conductivity when producing a material with enhanced mechanical strength, we have studied the thermal conductivity of ECAP processed copper. Figure 7 shows clearly that there is no significant loss of thermal conductivity after ECAP. The variations of conductivity with the number of ECAP passes may correspond to slight variations in the grain size distribution, cf. Figure 1, which can be explained in terms of the concomitant variation of the electron reflectivity. ${ }^{6)}$ The simple model used can be described as follows:

A simple one-dimensional chain of $N$ grains of equal size $l$, total length $L=N l$ and cross-sectional area $S$ can be assumed. The overall thermal resistance of this chain can be expressed as:

$$
R=\frac{L}{S \kappa_{\text {bulk }}}+N R_{\text {disl }}=\frac{L}{S \kappa_{\text {bulk }}}+\frac{L}{l} R_{\text {disl }}
$$


(a)

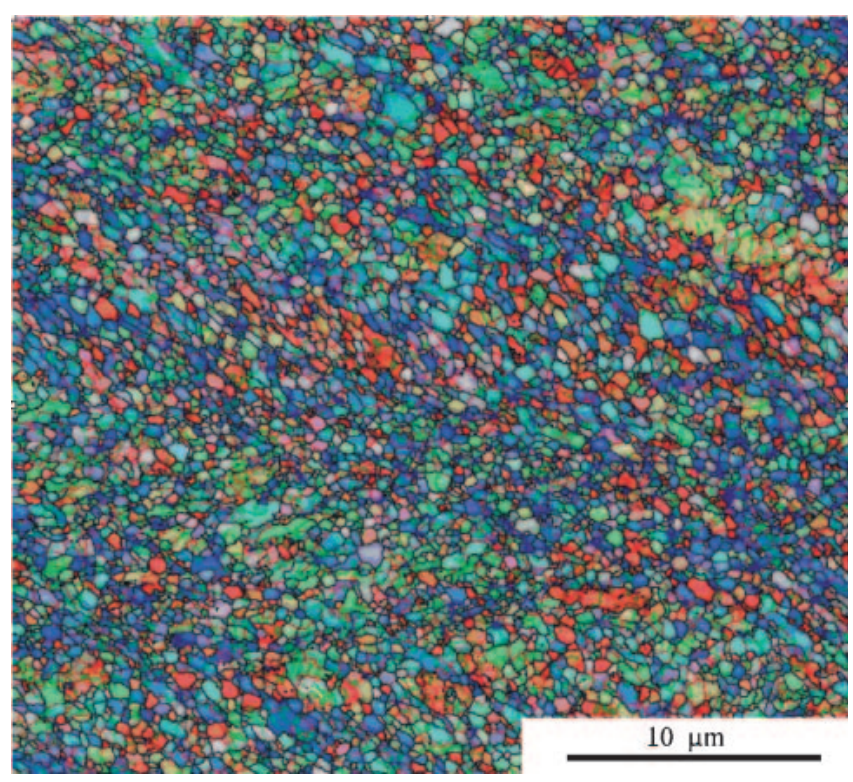

(b)

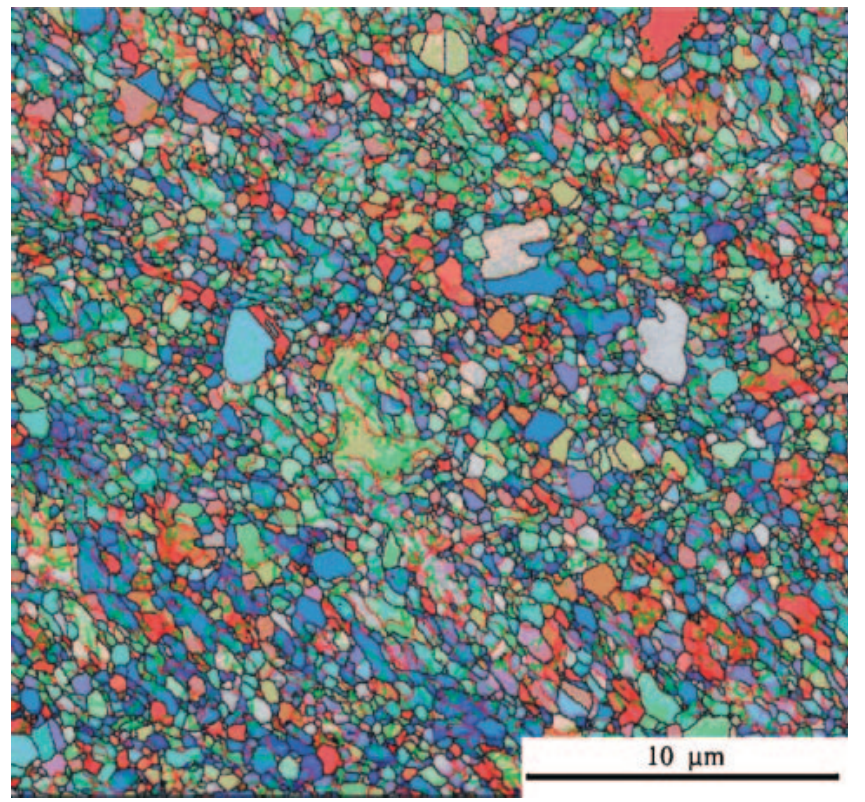

(c)

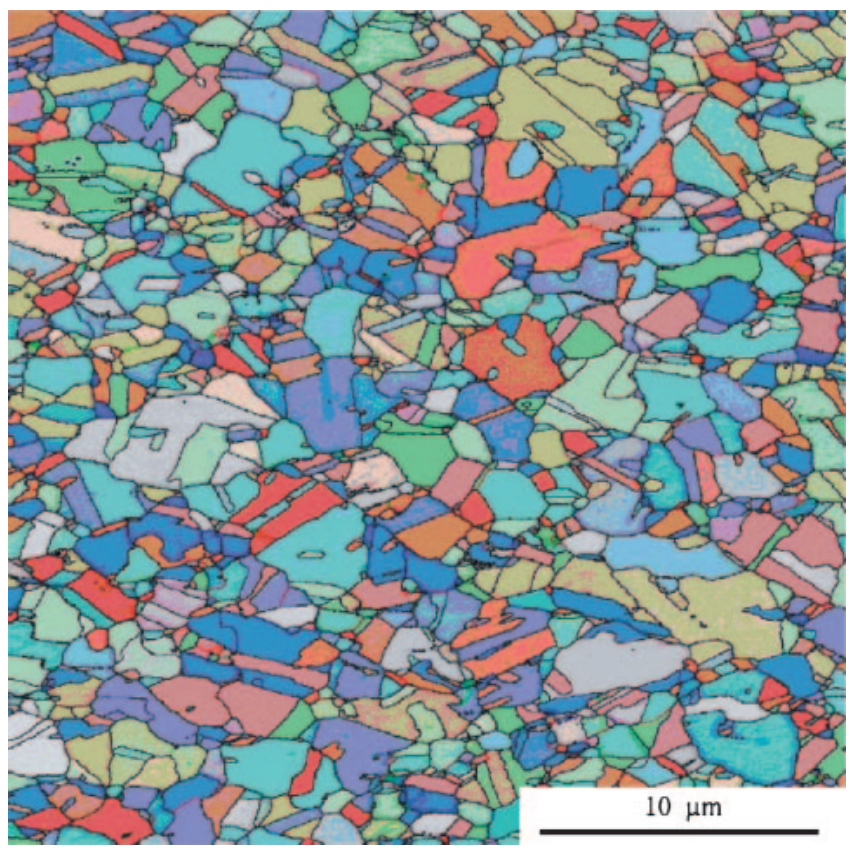

Fig. 5 EBSD orientation images of the 8 pass specimens after isochronal annealing $(10 \mathrm{~min})$ at (a) $110^{\circ} \mathrm{C}$, at (b) $150^{\circ} \mathrm{C}$ and at (c) $170^{\circ} \mathrm{C}$.

where $\kappa_{\text {bulk }}$ is the bulk heat conductivity and $R_{\text {disl }}$ is the thermal resistance due to dislocations, other contributions to resistivity being neglected. To evaluate $R_{\text {disl }}$, one can assume that the electrical and thermal conductivity for an electron gas are proportional to each other according to the Wiedemann-Franz law. As the majority of the dislocations are organised in cell walls (which at sufficiently large strains will have transformed to grain boundaries), published estimates $^{11,12)}$ of the grain boundary electrical resistance may be used:

$$
R_{\text {disl }}=\frac{4 \lambda}{3 A \kappa_{b u l k}(1-r)}
$$

Here $\lambda$ is the electron mean free path, $A$ the contact area and $r$ the electron reflectivity. This parameter takes into account the fact that the electrons reflected from the grain boundary dislocations do not take part in the transfer process.

The grain surfaces exhibit a complex geometry, and the effective partial contact area may be expressed as $A=x S$, with $x<1$. Combining (1) and (2) gives:

$$
R=\frac{L}{S \kappa_{b u l k}}\left(1+\frac{4 \lambda}{3 x l(1-r)}\right)
$$

The experimentally measured effective thermal conductivity $\kappa_{\text {exp }}$ (which is presented in Fig. 7) can be introduced via the equation 


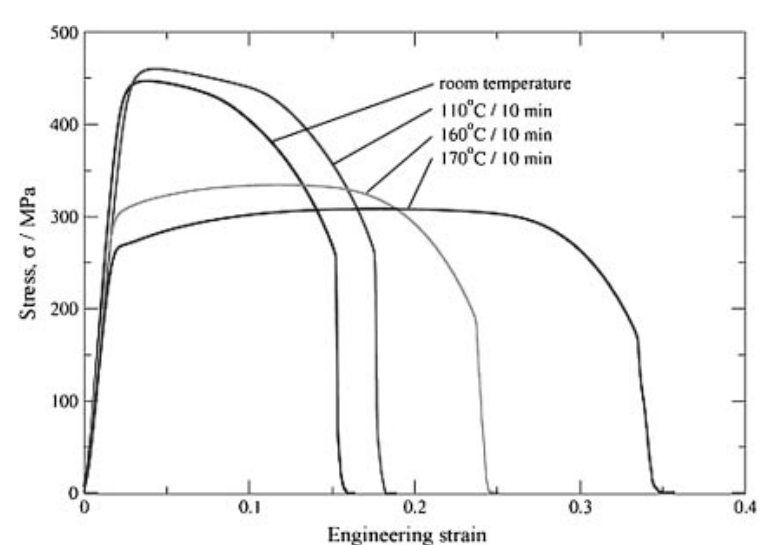

Fig. 6 Tensile deformation behaviour of ECAP processed copper (8 passes) after isochronal annealing.

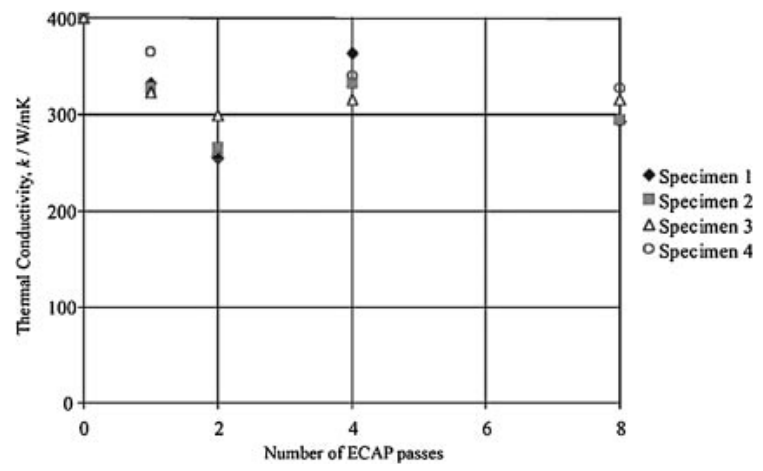

Fig. 7 Variation of thermal conductivity with increasing number of ECAP passes. ${ }^{6}$

$$
R=\frac{L}{S \kappa_{\exp }}
$$

leading to

$$
\kappa_{\exp }=\frac{\kappa_{\text {bulk }}}{1+\frac{4 \lambda}{3 x l(1-r)}}
$$

As $l$ can be identified with the grain size, and $\kappa_{\text {bulk }}=$ $400 \mathrm{~W} / \mathrm{mK}$ and $\lambda=39 \mathrm{~nm}$ at room temperature ${ }^{13)}$ are given, the only remaining variable influencing the thermal conductivity is the electron reflectivity. According to,${ }^{6)}$ differences in $r$ correspond to differences in the width of grain size distribution functions, as this influences the matching between boundaries of neighboring grains.

\subsection{Effect of ECAP on corrosion resistance}

Another aspect which is important for the application of copper is its corrosion resistance. The question arises of how the grain refinement, which improves the strength of the material very well, may influence the overall corrosion behaviour. Therefore, potentiodynamic investigations of the corrosion behaviour of copper before and after 8 ECAP passes were carried out. ${ }^{7,14)}$ We summarise the results of these studies here. Potentiodynamic polarisation curves of the coarse grained (CG) and the ECAP processed, ultrafine grained (UFG) copper in the $1 \mathrm{kmol} / \mathrm{m}^{3} \mathrm{H}_{2} \mathrm{SO}_{4}$ solution are presented in Fig. 8. Both specimens exhibit similar polar-

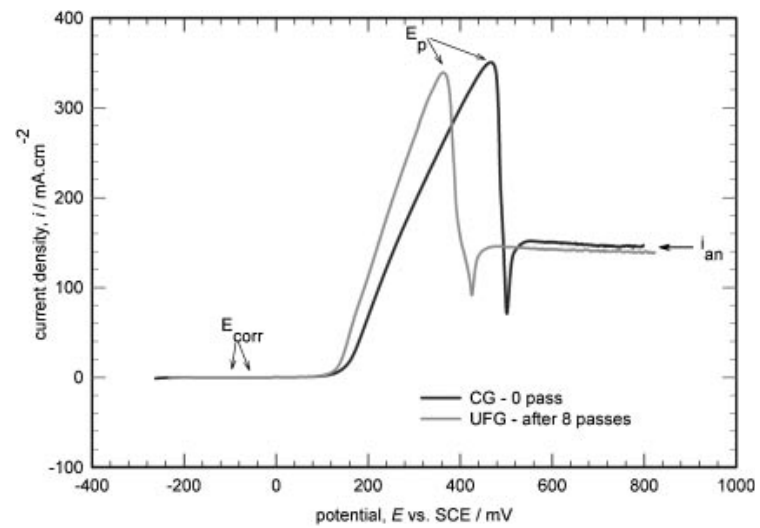

Fig. 8 Potentiodynamic curves $\left(1 \mathrm{kmol} / \mathrm{m}^{3} \mathrm{H}_{2} \mathrm{SO}_{4}\right)$ of technical purity copper before and after ECAP processing.

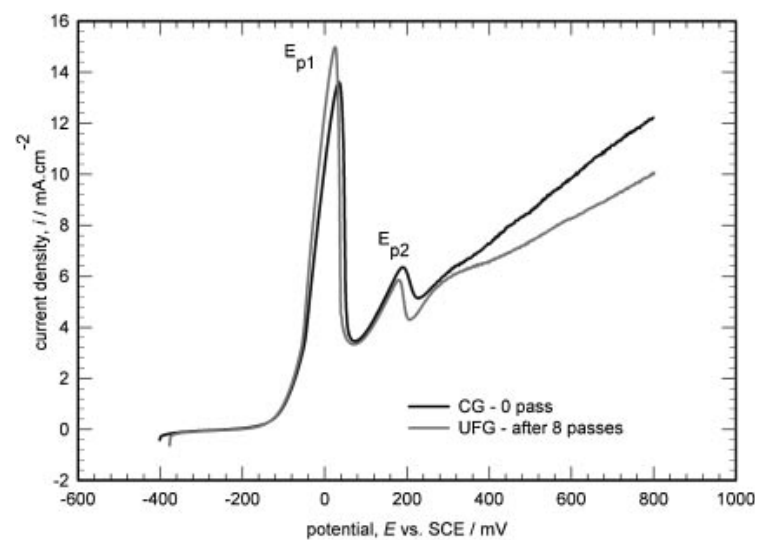

Fig. 9 Potentiodynamic curves $(3 \% \mathrm{NaCl})$ of technical purity copper before and after ECAP processing.

isation behaviour showing a single active-passive transition between 350 and $450 \mathrm{mV}_{\mathrm{SCE}}$. Upon reaching the passivation potential, a steady state anodic current is observed.

The corrosion behaviour in a $3 \% \mathrm{NaCl}$ solution $(\mathrm{pH}=$ 7.01) is shown in Fig. 9. In this case, two distinct activepassive transition potentials were observed. The potential $E_{\mathrm{p} 1}$ can be attributed to the formation of a $\mathrm{CuO}$ film on the specimen surface, ${ }^{15)}$ while $E_{\mathrm{p} 2}$ may be associated with copper oxidation to $\mathrm{Cu}_{2} \mathrm{O}_{3}$. Again, both materials exhibit very similar curves indicating that there is no pronounced effect of ECAP on the overall corrosion behaviour.

A more detailed comparison in terms of commonly used corrosion parameters, viz. the corrosion potential $E_{\text {corr }}$, the corrosion current density $i_{\text {corr }}$ and the already mentioned active-passive transition potentials, cf. Table 1, also shows that there is almost no difference in the corrosion behaviour between the ECAP processed and the coarse grained copper.

To investigate the local patterns of the corrosion attack, SEM pictures were taken after the corrosion experiments (Fig. 10). On the left-hand side, where the surface of the ECAP processed copper is presented, it is seen that a uniform corrosion attack had occurred, no preferential corrosion attack at the grain boundaries being recognisable. In contrast, the surface of a non-ECAP processed specimen (right-hand side micrograph in Fig. 10) shows distinct localisation of corrosion attack at the grain boundaries, while significantly 
Table 1 Corrosion characteristics of the coarse grained and the ECAP processed copper in the two solutions used. ${ }^{14)}$

\begin{tabular}{|c|c|c|c|c|}
\hline $1 \mathrm{kmol} / \mathrm{m}^{3} \mathrm{H}_{2} \mathrm{SO}_{4}$ & $E_{\text {corr }}[\mathrm{mV}]$ & $i_{\text {corr }}\left[\mu \mathrm{A} / \mathrm{cm}^{2}\right]$ & $i_{\mathrm{an}}\left[\mu \mathrm{A} / \mathrm{cm}^{2}\right]$ & $E_{\mathrm{p}}[\mathrm{mV}]$ \\
\hline coarse grained & -79 & 45 & 159 & 470 \\
\hline 8 ECAP passes & -54 & 30 & 142 & 361 \\
\hline $3 \% \mathrm{NaCl}$ & $E_{\text {corr }}[\mathrm{mV}]$ & $i_{\text {corr }}\left[\mu \mathrm{A} / \mathrm{cm}^{2}\right]$ & $i_{\text {an }}\left[\mu \mathrm{A} / \mathrm{cm}^{2}\right]$ & $E_{\mathrm{p} 1} / E_{\mathrm{p} 2}[\mathrm{mV}]$ \\
\hline coarse grained & -234 & 23 & $6-12$ & $37 / 195$ \\
\hline
\end{tabular}
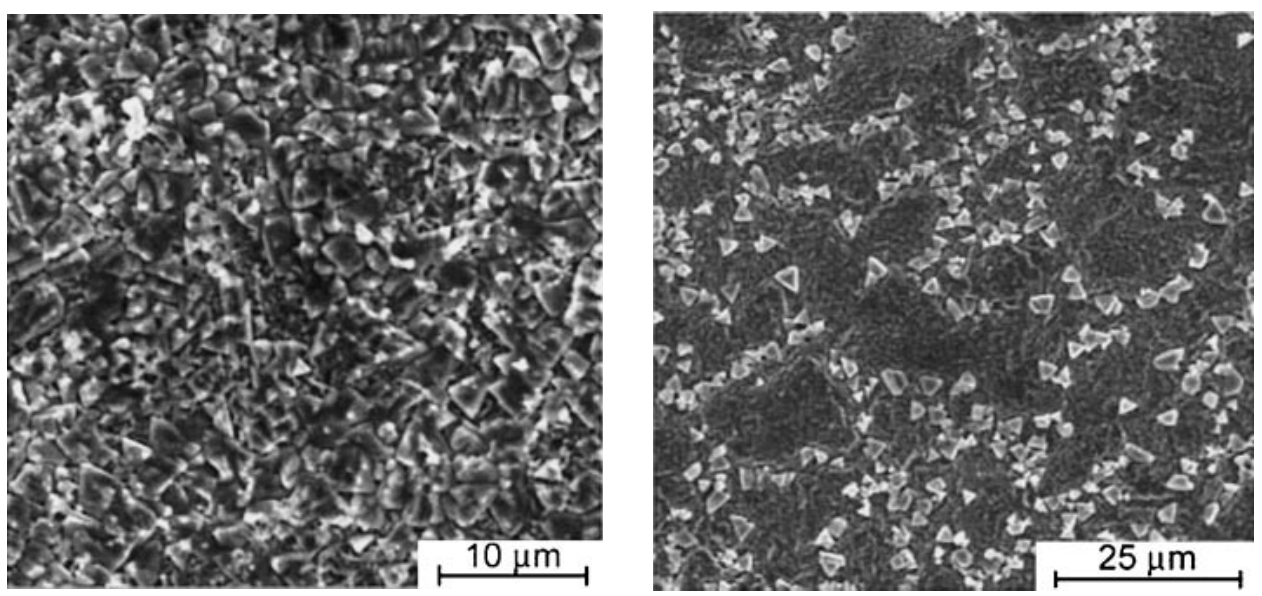

Fig. 10 SEM micrographs after the corrosion tests showing the difference in the character of corrosion attack, left: after 8 ECAP passes, right: coarse grained copper.

lower corrosion damage is seen in the grain interior regions. The more homogeneous corrosion damage in case of ECAP processed copper in contrast with the localised corrosion attack in conventional copper can obviously be seen as an advantage.

In assessing the overall effect of grain refinement by ECAP on the corrosion properties of copper, the following major outcomes of the tests can be reported. From the thermodynamic viewpoint both potentials (the corrosion and the passivation one) of UFG copper are shifted to positive values with respect to the corresponding potentials of $\mathrm{CG}$ copper, which signifies an improvement in corrosion resistance. From the kinetic viewpoint the influence of ECAP on the corrosion current density and the steady state current density in the passive state is not so obvious, however. The results of the electrochemical tests reported here characterise the surface of the material in a short-term. From the character of the corrosion attack on the surface of the UFG and the CG copper seen in Fig. 10 one may conjecture that the long-term progress of the corrosion attack will be affected by the formation of a layer of corrosion products (passive and/or pseudopassive layer). This layer will be more homogeneous in the ECAP processed copper due to its ultra fine grain size. It can thus be expected that in long-term corrosion resistance tests the corrosion rate will drop below the levels for the coarse-grained copper. Such behaviour was, indeed, found by other authors for ECAP processed titanium. ${ }^{16)}$ They found unambiguously that in all corrosive media tested the corrosion rate of UFG specimens was lower than that of the coarse-grained reference material.

\section{Conclusion}

In this paper several aspects of the effect of ECAP on the properties of technical purity copper have been reviewed and summarised. Having in mind industrial applications of copper, e.g. in connectors or sputtering targets, the material's portrait presented in this paper is quite promising. ECAP leads to extreme structural refinement of copper, down to the grain size of about $200 \mathrm{~nm}$. This gives rise to a huge increase in strength, but causes a low ductility level. It was shown that a suitable heat treatment can partly restore ductility, while still maintaining a very high strength.

At moderate temperatures the ECAP processed copper was found to retain its grain structure and properties, while at about $150^{\circ} \mathrm{C}$ and above recrystallisation was observed.

The overall favourable assessment of the effect of ECAP on the properties is also based on the fact that ECAP does not lead to any sizeable deterioration of thermal conductivity. It can be conjectured that electrical conductivity is not strongly affected in a negative way either.

Finally, it was shown that ECAP has no detrimental effect on the overall corrosion behaviour in $1 \mathrm{kmol} / \mathrm{m}^{3} \mathrm{H}_{2} \mathrm{SO}_{4}$ and $3 \% \mathrm{NaCl}$ solutions. Localisation of the corrosion attack at the grain boundaries was only observed in coarse grained copper. ECAP processed copper exhibited a more homogeneous corrosion behaviour.

It can thus be concluded that a very favourable combination of properties of technical purity copper can be obtained by equal channel angular pressing, which-together with subsequent heat treatment-permits tailoring of the properties within a certain range of practical interest. 


\section{Acknowledgements}

YE and RJH gratefully acknowledge financial support from DFG through the Forschergruppe 544 "Mechanische Eigenschaften und Grenzflächen ultrafeinkörniger Werkstoffe". MJ acknowledges financial support by GACR through the grant 106/05/2347. Partial support by the grant DAAD-AVCR D8-CZ5/06-07 is also acknowledged.

Experimental assistance of Zuzana Zuberova and Torbjørn Lamark is gratefully acknowledged.

\section{REFERENCES}

1) R. Z. Valiev, Y. Estrin, Z. Horita, T. G. Langdon, M. J. Zehetbauer and Y. T. Zhu: Journal of Metals (JOM) 58 (4) (2006) 33-39.

2) R. Z. Valiev, R. K. Islamgaliev and I. V. Alexandrov: Prog. Mater Sci. 45 (2000) 103-189.

3) Z. Horita, K. Ohashi, T. Fujita, K. Kaneko and T. G. Langdon: Adv. Mater. 17 (2005) 1599.
4) H. Ferkel, M. Glatzer, Y. Estrin, R. Z. Valiev, C. Blawert and B. L. Mordike: Mater. Sci. Eng. A348 (2003) 100-110.

5) E. Litovsky and M. Shapiro: J. Am. Ceram. Soc. 7 (1992) 3425-3439.

6) O. V. Gendelman, M. Shapiro, Y. Estrin, R. J. Hellmig and S. Lekhtmakher: Mater. Sci. Eng. A434 (2006) 88-94.

7) M. Janecek, B. Hadzima, R. J. Hellmig and Y. Estrin: Kovove Mater. 43 (2005) 258-271.

8) O. V. Mishin, DJ Jensen and N. Hansen: Mater. Sci. Eng. A342 (2003) 320-328.

9) Y. M. Wang, M. W. Chen, F. H. Zhou and E. Ma: Nature 419 (2002) 912-915.

10) H. Mughrabi, H. W. Höppel, M. Kautz and R. Z. Valiev: Z. Metallkunde 94 (2003) 1079-1083.

11) A. Bietsch and B. Michel: Appl. Phys. Lett. 80 (2002) 3346-3348.

12) Y. V. Sharvin: JETP 21 (1965) 655

13) A. P. Zhilyaev, B. K. Kim, J. A. Szpunar, M. D. Baro and T. G. Langdon: Mater. Sci. Eng. A391 (2005) 377-389.

14) B. Hadzima, M. Janecek, R. J. Hellmig, Y. Kutnyakova and Y. Estrin: Mater. Sci. Forum 503-504 (2006) 883-888.

15) H. P. Leckie: J. Electrochem. Soc. 117 (1970) 1478.

16) A. Balyanov, J. Kutnyakova, N. A. Amirkhanova, V. V. Stolyarov, R. Z. Valiev, X. Z. Liao, Y. H. Zhao, Y. B. Jiang, H. F. Xu, T. C. Lowe and Y. T. Zhu: Scripta Materialia 51 (2004) 225-229. 